\title{
Role of rRAB22b, an Oligodendrocyte Protein, in Regulation of Transport of Vesicles From Trans Golgi to Endocytic Compartments
}

\author{
A.G. Rodriguez-Gabin, ${ }^{1}$ M. Cammer, ${ }^{2}$ G. Almazan, ${ }^{3}$ M. Charron, ${ }^{4}$ and J.N. Larocca ${ }^{1 \star}$ \\ ${ }^{1}$ Department of Neurology/Neuroscience, Albert Einstein College of Medicine, Bronx, New York \\ ${ }^{2}$ Analytical Imaging Facility, Albert Einstein College of Medicine, Bronx, New York \\ ${ }^{3}$ Department of Pharmacology and Therapeutics, McGill University, Montreal, Quebec, Canada \\ ${ }^{4}$ Department of Biochemistry, Albert Einstein College of Medicine, Bronx, New York
}

\begin{abstract}
Intracellular membrane trafficking plays an essential role in the biogenesis and maintenance of myelin. Members of the Rab protein family are important components of the systems that regulate intracellular vesicle transport. We examine the function of $r$ Rab22b, a novel rat Rab protein cloned from an oligodendrocyte cDNA library, by visualizing and identifying in living Hela cells the organelles that contain rRab22b. Our results show that rRab22b is present in the trans Golgi/TGN and endocytic compartments. Trafficking of membranes from trans Golgi to endocytic compartments takes place via small tubulo vesicular organelles containing rRab22b. The formation of vesicles in the trans Golgi also appears to be regulated by rRab22b. Additionally, our results suggest that $r$ Rab22b controls the transport of vesicles from the trans Golgi to endocytic compartments that localize in oligodendrocyte processes. That $r$ Rab22b is involved in the transport of certain proteins from trans Golgi to myelin is suggested by the evidence that certain proteins being targeted to the plasma membrane are first transported from trans Golgi to endocytic compartments. J. Neurosci. Res. 66:1149-1160, 2001. @ 2001 Wiley-Liss, Inc.
\end{abstract}

Key words: Rab proteins; vesicle transport; oligodendrocytes; signaling, myelin; endosomes; trans Golgi; myelin proteins

Myelin is a multilamellar structure that surrounds axon segments and is essential for saltatory conduction of the electrical impulse along the axon. In the central nervous tissue (CNS), myelin arises from cellular processes that extend from the oligodendrocyte perikaryon and wrap in a spiral fashion around segments of the axon. Myelin is not formed as a unit; individual components are synthesized in different cellular compartments, sorted out and transported to the site of myelin formation by several different mechanisms (Benjamins and Smith, 1984; Morel et al., 1994). Myelin basic protein (MBP) is synthesized close to the site of myelin assembly (Colman et al., 1982; Barbarese et al., 1995). In contrast, the proteolipid protein
(PLP) and both isoform, large and small, of myelin associated glycoprotein (MAGs) are synthesized in the endoplasmic reticulum, then transported via vesicles to the Golgi and finally from the Golgi to myelin (Townsend and Benjamins, 1983; Trapp et al., 1989). Similarly, evidence suggests that certain myelin lipids such as sulfatides are synthesized in the Golgi and then transported to myelin via membranous vesicles (Townsend et al., 1984; Sato et al., 1986). In eukaryotic cells, vesicle transport is regulated by control of vesicle budding and fusion (Nuoffer and Balch, 1994; Rothman and Wieland, 1996). Additionally, movement along microtubules and microfilaments of the cytoskeleton (Cole and Lippincott-Schwartz, 1995) facilitates the transport of vesicles. Despite much knowledge of the biochemistry and cell biology of oligodendrocytes, the signaling systems that regulate intracellular membrane trafficking and its coordination with changes in cell shape remain largely unknown. Rab proteins are key components in mechanisms that regulate intracellular membrane trafficking. Each member of this family of proteins is specifically localized to a particular membrane trafficking pathway. Their functions depend on their ability to alternate between two conformational states, inactive (GDPbound) and active (GTP-bound) (Bourne et al., 1990) and also on their capacity to associate reversibly with specific membrane compartments (Ossig et al., 1995).

In the present study, we identify membrane transport processes regulated by $\mathrm{rRab} 22 \mathrm{~b}$, a novel $\mathrm{Rab}$ protein cloned from rat oligodendrocyte cultures. The role of

Contract grant sponsor: NMS; Contract grant number: RG 1941; Contract grant sponsor: NSF; Contract grant number: ABN-9983255; Contract grant sponsor: NIH; Contract grant number: DK47245; Contract grant sponsor: AECOM Cancer Center; Contract grant number: 5P30CA13330; Contract grant sponsor: MRC; Contract grant number: MT-12734.

${ }^{\star}$ Correspondence to: J.N. Larocca, Department of Neurology and Neuroscience, AECOM, Yeshiva University, 1300 Morris Park Ave, New York, NY 10461. E-mail: larocca@aecom.yu.edu

Received 9 May 2001; Accepted 21 May 2001 
$\mathrm{rRab} 22 \mathrm{~b}$ in the regulation of transport vesicles containing this protein was assessed. We examined living cells using a chimeric protein of $r$ Rab22b with EYFP (a variant of the green fluorescent protein). rRab22b-EYFP was transiently expressed in Hela cells and rat oligodendrocytes and organelles containing rRab22b were visualized by fluorescent microscopy. Their morphologic changes and movements were observed in Hela cells imaging over short time periods to visualize the budding of vesicles from the donor compartment and vesicle fusion in the acceptor compartment. Organelles were visualized containing both rRab22b-EYFP and other intracellular markers tagged with ECFP including Rab8 (trans Golgi network), pECFP-Golgi (trans-Golgi), Rab5b (early endosomes), and $\mathrm{Rab} 7$ (late endosomes).

Our observations show the presence of rRab22b in trans Golgi/TGN, in early endosomes and in late endosomes. The traffic of membranes between trans Golgi/ TGN and endocytic compartments occurs via small tubular vesicles traveling along microtubules. Our results also suggest that $\mathrm{rRab} 22 \mathrm{~b}$ synchronizes the trafficking of membranes from the trans Golgi to endocytic compartments regulating vesicle formation in the trans Golgi.

\section{EXPERIMENTAL PROCEDURES}

\section{Library Screening}

The cDNA oligodendrocyte library was plated out on a culture of XL1-Blue cells at a density of $5 \times 10^{4}$ plaque forming units per Petri dish (150 mm-diameter). Plaque lifts were performed in duplicate using nitrocellulose filters (Maniatis et al., 1989). The nitrocellulose filters were probed, under conditions of high stringency (Wallace et al., 1981) with ${ }^{32}$ P-labeled PCR-generated probes. Briefly, the nitrocellulose filters containing immobilized DNA were preincubated in $50 \%$ deionized formamide, $50 \mathrm{mM} \mathrm{Na}_{2} \mathrm{HPO}_{4}, \mathrm{pH} 7.4,750 \mathrm{mM} \mathrm{NaCl}, 1 \mathrm{mM}$ EDTA, $5 \times$ Denhardt's $(1 \times$ Denhardt's is $0.2 \mathrm{~g} / \mathrm{l}$ polyvinylpyrrolidone, $0.2 \mathrm{~g} / 1$ bovine serum albumin, $0.2 \mathrm{~g} / 1$ Ficoll 400), $0.1 \%$ SDS, $100 \mu \mathrm{g} / \mathrm{ml}$ poly(A), and $100 \mu \mathrm{g} / \mathrm{ml}$ heatdenatured salmon sperm DNA at $42^{\circ} \mathrm{C}$ for $1 \mathrm{hr}$, and then further incubated in the above solution with $1-2 \times 10^{6}$ $\mathrm{cpm} / \mathrm{ml}$ of PCR-constructed probe for $12-16 \mathrm{hr}$ at $42^{\circ} \mathrm{C}$. Filters were washed twice at $22^{\circ} \mathrm{C}$ in $2 \times$ SSC $(\mathrm{SSC}=$ $15 \mathrm{mM} \mathrm{NaCitrate,} \mathrm{pH} 7.00,150 \mathrm{mM} \mathrm{NaCl}), 0.1 \%$ SDS at $50^{\circ} \mathrm{C}$. To reveal the positive clones the washed filters were exposed to XAR film with an intensifying screen at $-70^{\circ} \mathrm{C}$ for $12-16 \mathrm{hr}$. Positive clones were purified by additional rounds of plating and hybridization as described above. The sequence of the insert of interest was performed in the DNA Sequencing Facility at Einstein using the ABI Prism ${ }^{\mathrm{TM}}$ dye terminator kit with AmpliTaq DNA polymerase.

\section{Northern Blot Analysis}

A multiple-tissue mRNA blot, loaded with approximately $2 \mu \mathrm{g}$ of poly A+ RNA from different rat tissues (Clontech), was prehybridized for $4 \mathrm{hr}$ at $50^{\circ} \mathrm{C}$ in Express Hybridization Buffer (Clontech) with single-stranded salmon testis DNA $(100 \mu \mathrm{g} / \mathrm{ml})$ and sequentially hybridized with ${ }^{32} \mathrm{P}-$ labeled rRab22b cDNA and a randomprimed probe derived from a $2-k b$ human b-actin probe for $4 \mathrm{hr}$ at $50^{\circ} \mathrm{C}$. The blot was sequentially washed under increasingly stringent conditions. The final wash was $30 \mathrm{~min}$ in $0.1 \times \mathrm{SSC}$ containing $0.1 \% \mathrm{SDS}$ at $65^{\circ} \mathrm{C}$. The washed membrane was expose to Biomax film from $10-60 \mathrm{hr}$ at $-70^{\circ} \mathrm{C}$. Similar procedure was used to detect rRab22b mRNA in blot containing $10 \mu \mathrm{g}$ of total RNA from different primary cell cultures of neural cells. Total RNA was isolated as described (Burcelin et al., 1997).

\section{DNA Construct}

The pEYFP-C1 vector (Clontech) was used to construct the rRab22b gene with the $\mathrm{N}$ terminal tagged with EYFP.

The $\mathrm{rRab} 22 \mathrm{~b}$ coding region was amplified by PCR from the lambda $\lambda$ gt11 phage containing the rRab22b cDNA using a $5^{\prime}$ primer containing a Xhol restriction endonuclease site and the first 20 nucleotides of the rRab22b coding region, and a $3^{\prime}$ primer containing a BamHI restriction endonuclease site and nucleotides complementary to the last 20 nucleotides of the rRab22b coding sequence, including the stop codon. The PCR was carried out as described (Burcelin et al., 1997). The PCR products were purified by agarose gel electrophoresis, and subcloned into $\mathrm{pGEMT}$ vector. The rRab22b cDNA was sequenced to determine the fidelity of the PCR amplification. Then the pGEMT plasmid containing rRab22b coding region was treated with Xhol and BamHI endonucleases. The rRab22b cDNA was purified and ligated into the Xhol and BamHI sites of the pEYFP-C1 mammalian expression vector.

Similar procedures were used for the construction of Rab5, 7, and 8 chimeras with ECFP. In these cases the sequences of the coding region were synthesized by RTPCR. Rat brain mRNA (Clontech) was converted into complementary DNA using MMLV-RT and poly dT as primer. The PCR was carried out with primers directed to the $\mathrm{N}$ and $\mathrm{C}$ terminal regions of the coding sequences containing Xhol and BamHI endonuclease restriction sites.

rRab22b site-directed mutagenesis was carried out according to the method of Ho et al. (1989).

\section{Primary Cell Cultures}

Primary astrocytes, microglia, oligodendrocyte progenitors, and oligodendrocyte cultures for isolation of total RNA, were established from newborn rat cerebral hemispheres as described by McCarthy and de Vellis (1980) with minor modifications (Burcelin et al., 1997).

Oligodendrocytes isolated from rat cerebral hemispheres from 12-day-old rats, as described previously (Berti Mattera et al., 1984), were used to express rRab22b-EYFP. Isolated oligodendrocytes were plated on chambered coverglasses coated with Matrigel (Collaborative Biomedical Products, New Bedford, MA) at a density of $5 \times 10^{4}$ cells (15 mm coverglasses) and maintained in defined serum-free medium consisting of a DMEM-F12 mixture (1:1), 10 mM HEPES, 0.1\% bovine serum albu- 
$\min$ (BSA), $25 \mu \mathrm{g} / \mathrm{ml}$ human transferrin, $30 \mathrm{nM}$ selenium, $20 \mathrm{nM}$ hydrocortisone, $20 \mathrm{nM}$ progesterone, $10 \mathrm{nM}$ biotin, $5 \mu \mathrm{g} / \mathrm{ml}$ insulin, $16 \mu \mathrm{g} / \mathrm{ml}$ putrescine, $30 \mathrm{nM}$ triiodothyronine and Gibco's mixture of trace elements. Oligodendrocytes were cultured for 3 days before gene transfer, and were maintained in cultures for $24-72 \mathrm{hr}$ before analysis of chimera expression by fluorescence microscopy.

\section{Hela Cell Cultures}

Hela cells (Epitheloid carcinoma, cervix, human, American Type Culture Collection) were maintained in MEM supplemented with 10\% FCS, 1\% essential amino acids, $2 \mathrm{mM}$ glutamine, $100 \mathrm{U} / \mathrm{ml}$ penicillin and $100 \mu \mathrm{g} / \mathrm{ml}$ streptomycin at $37^{\circ} \mathrm{C}$ in a $5 \% \mathrm{CO}_{2}$ incubator.

For the realization of the transfection experiments Hela cells were plated on $15 \mathrm{~mm}$ coverglasses at a density $0.4-1.6 \times 10^{5}$ cells for $24 \mathrm{hr}$ before transfection.

\section{Transfection}

Hela cells were transfected using SuperFect transfection reagent (Qiagen) according to the manufacturer's indications. Briefly, cultures were treated with $1.2 \mathrm{ml}$ of growth media containing the DNA-SuperFect complex (3 $\mu \mathrm{g}$ DNA $/ 37.5 \mu \mathrm{g}$ SuperFect) at $37^{\circ} \mathrm{C}$ for $60 \mathrm{~min}$.

Oligodendrocytes were transfected using Lipofectamine Plus (GIBCO BRL, Gaithersburg, MD), according to the instructions of the manufacturer. Oligodendrocytes were treated with $1.2 \mathrm{ml}$ culture media containing $2.5 \mu \mathrm{g}$ of DNA, $12.5 \mu \mathrm{g}$ of lipofectamine and $10 \mu \mathrm{l}$ of Plus reagent at $37^{\circ} \mathrm{C}$ for $3-6 \mathrm{hr}$.

\section{Fluorescence Microscopy Analysis of Living Cells}

Cells were imaged in culture medium without phenol red at $37^{\circ} \mathrm{C}$ using an Olympus I $\times 70$ microscope with a $60 \times$ Olympus Planapo oil immersion objective NA 1.4 and equipped with a CCD camera (Photometrics KAF 1400 PXL liquid cooled). Cells expressing ECFP chimeras were excited using the $436 \pm 20$ filter (Chroma Technology) and imaged with a filter $480 \pm 40$ (Chroma Technology). The exciter filter $500 \pm 20$ and emitter filter $535 \pm 30$ (Chroma Technology) were used to visualize EYFP chimeras. Temperature was controlled with a Nevtek air stream stage incubator (Burnsville, VA). Images from the CCD camera were digitized and collected directly to RAM with an Apple Power Macintosh 8500. Image capturing, processing, and automatic and manual data acquisition was performed using I.P. Lab Spectrum software.

\section{RESULTS}

\section{Cloning of rRab22b cDNA}

In a previous study using RT-PCR we identified a cDNA fragment, Rab0, as a novel Rab sequence expressed in rat oligodendrocytes (Burcelin et al., 1997). Because the Rab0 sequence has high identity to human $\mathrm{Rab} 22 \mathrm{~b}$ we are redesignating $\mathrm{Rab0}$ as rat $\mathrm{Rab} 22 \mathrm{~b}$ (rRab22b).
The complete sequence of $\mathrm{rRab} 22 \mathrm{~b}$ was obtained by screening a rat oligodendrocyte $\lambda g t 11$ cDNA library obtained from Dr. A. Campagnoni (Baba et al., 1995). The clones of interest were detected by probing the cDNA library with a radioactive rRab22b cDNA fragment. The cDNA fragment, used as probe, was labeled with $\left[{ }^{32} \mathrm{P}\right] \mathrm{dCTP}$ by PCR using specific primers targeted to the $5^{\prime}$ and $3^{\prime}$ terminals of a $180 \mathrm{bp}$ Rab fragment, and the nitrocellulose filters were hybridized overnight at $42^{\circ} \mathrm{C}$. Positive plaques were purified by a second round of screening. Two positive clones were found among the $0.5 \times 10^{6}$ plaques screened, and these were plaquepurified. Both phages contained inserts of approximately 3,600 bases (results not shown). The inserts were sequenced and the sequences analyzed with University of Wisconsin GCG programs.

The cDNA sequence of $\mathrm{rRab} 22 \mathrm{~b}$ revealed an open reading frame of $582 \mathrm{bp}$ and the deduced amino acid sequence indicated a protein containing 194 amino acids (GenBank accession number AF254800) (Fig. 1a,b) with a molecular weight of $21.6 \mathrm{kDa}$ and an isoelectric point of 7.05 .

The deduced amino acid sequence of rRab22b contains both the four motifs that participate in the formation of the GTP-binding site in the superfamily of Ras-like proteins and the domain required for effector protein interaction (Fig. 1b). Analysis of the effector domain indicated that $r$ Rab22b is a member of the Rab family of GTP-binding proteins. The carboxyl terminal region contains an isoprenylation motif, suggesting a protein that is targeted to membrane compartments (Fig. 1b). A comparison of the $r$ Rab22b sequence with a closely related Rab cDNA (human Rab 22b (Chen et al., 1996)) showed 88\% identity; the predicted amino acid sequence had $94 \%$ identity. These results suggest that $\mathrm{rRab} 22 \mathrm{~b}$ encodes the rat homolog of human Rab22b. In view of the fact that a segment of the $\mathrm{C}$ terminal domain shows 9 differences among the 14 residues, however, one must consider that rRab22b may very well encode a new member of the Rab family. This segment is part of the motif responsible for the targeting of $\mathrm{Rab}$ proteins to specific membrane compartments (Chavrier et al., 1991).

\section{Analysis of Rat Rab22b Expression}

Expression of $r R a b 22 b$ mRNAs was analyzed by Northern blots. Nylon membranes containing mRNA from several rat tissues were probed with $\left[{ }^{32} \mathrm{P}\right] \mathrm{dCTP}$ labeled rRab22b cDNA. A band of approximately 3,600 $\mathrm{bp}$ had the highest level of expression in brain, followed in decreasing order by heart, testis, kidney, lung, and spleen (Fig. 2a). None was detected in either liver or skeletal muscle.

Rat Rab22b mRNA expression was assessed in primary cultures of oligodendrocytes, oligodendrocyte progenitors, microglia and astrocytes by probing total RNA with labeled rRab22b cDNA (Fig. 2c). Oligodendrocytes showed a strong band of 3,600 bp and a weaker band in oligodendrocyte progenitors, microglia, and astrocytes. That these differences in rRab22b mRNAs were not due 


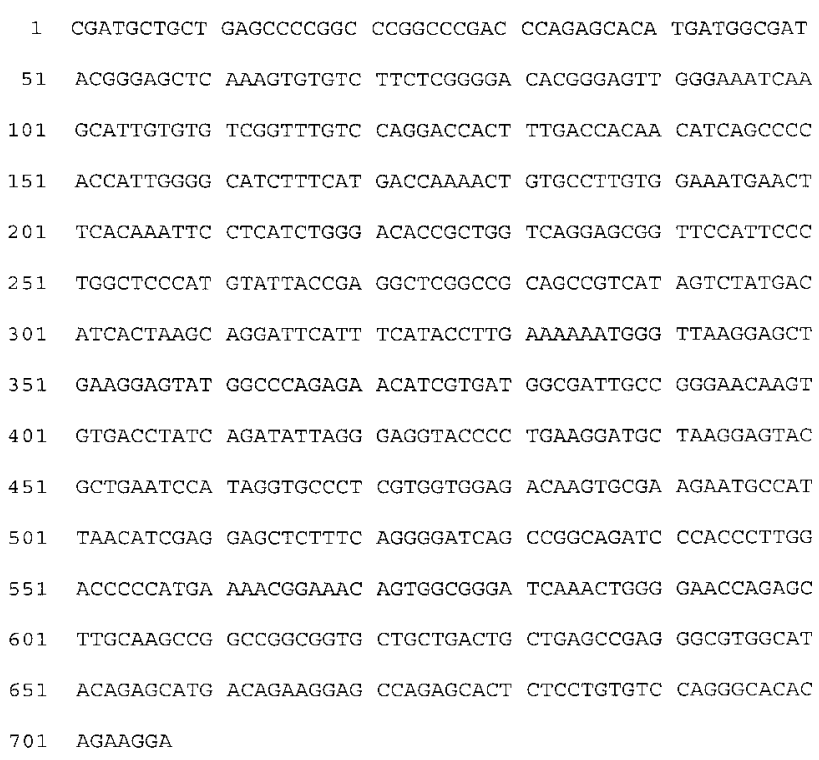

b

\begin{abstract}
1. MAIRELKVCL LGDTGVGKSS IVCRFVQDHF DHNISPTIGA SFMTKTVPCG
51 NELHKFLIWDT AGQERFHSL APMYYRGSAA AVIVYDITKQ DSFHTLKKWV

101 KELKEYGPEN IVMAIAGNKC DLSDIREVPL KDAKEYAESI GALVVETSAK

151 NAINIEELFQ GISRQIPPLD PHENGNSGGI KLGNQSLQAG RRCC
\end{abstract}

Fig. 1. The deduced amino acid sequence indicates that $\mathrm{rRab} 22 \mathrm{~b}$ is a novel rat Rab protein (GenBank accession number AF254800). A: Nucleotide sequence of $\mathrm{rRab} 22 \mathrm{~b}$. B: Deduced amino acid sequence of rRab22b. Lines indicate conserved GTP-binding domains. Bold letters denote effector domain.

to RNA degradation was established by the similarity in $\beta$ actin mRNAs from tissue and cell culture samples (Fig. $2 b, d)$.

\section{Visualization of Organelles Containing rRab22b}

To identify the vesicle transport process regulated by rRab22b we studied its localization in intracellular vesicles. First we tagged rRab22b at the N-terminal by constructing a chimera protein of $\mathrm{rRab} 22 \mathrm{~b}$ with EYFP (a yellow variant of green fluorescent protein) and then we expressed the chimeric protein in Hela cells. With the tagged protein we could visualize in living cells the organelles containing rRab22b. This method avoided limitations inherent in staining with polyclonal antibodies, such as the low concentration of antigens and cross reactivity with undefined but closely related proteins.

rRab22b tagged with EYFP was first transiently expressed in Hela cells and its intracellular localization analyzed by fluorescence microscopy. Hela cells were used a

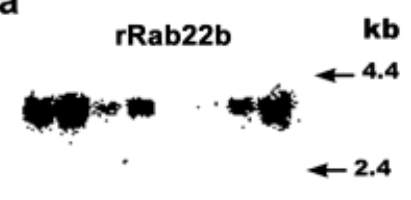

He Br Sp Lu Li Mu Ki Te

C

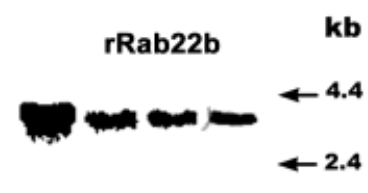

OI Op As Mi b

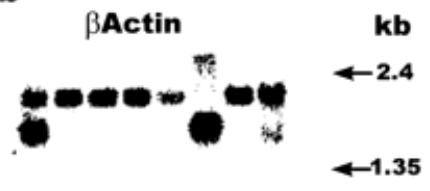

He Br Sp Lu Li Mu Ki Te

d

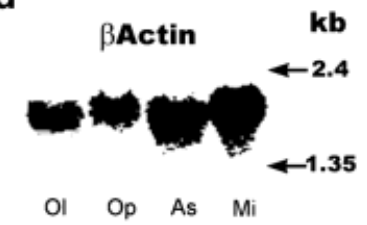

Fig. 2. Determination of $\mathrm{rRab} 22 \mathrm{~b}$ mRNA expression by Northern blot analysis in rat tissues and cell primary cultures. A,B: The membrane contains (approximately $2 \mu \mathrm{g}$ /lane) mRNA in lanes isolated from: He, heart; Br, brain; Sp, spleen; Lu, lung; Li, liver; Mu, skeletal muscle; Ki, kidney; Te, testis. C,D: The membrane contains total RNA (approximately $10 \mu \mathrm{g} /$ per lane) in lanes isolated from rat primary cultures; Ol, oligodendrocytes; Op, oligodendrocyte progenitors; As, astrocytes and $\mathrm{Mi}$, microglia. The membranes were probed with $\left[{ }^{32} \mathrm{P}\right]$ dCTP labeled rRab22b cDNA (A,C) or with $\left[{ }^{32} \mathrm{P}\right]$ dCTP labeled $\beta$-actin (B,D). The mobility's of ssRNA size markers are indicated in $\mathrm{kb}$, right margin of the pictures.

because: 1) Hela cell cultures are easily maintained; 2) Hela cells efficiently express fusion proteins; and 3) the large size of Hela cells facilitates visualization and analysis of the movement of organelles containing proteins of interest. Expression of oligodendrocyte proteins in other types of cells have been used by several laboratories to study the transport or function of oligodendrocyte proteins (Filbin et al., 1990; Gow and Lazzarini, 1996; Pedraza et al., 1997).

Transfection of the rRab22b-EYFP chimera did not increase the number of dead cells, nor was there any change in cell shape. Approximately 35\% of the cells expressed the chimera protein and expression was maintained for at least 7 days.

We found that the rRab22b-EYFP chimera localized mainly in large asymmetrical vesicular structures close to the nucleus (Fig. 3a,c). Spherical vesicles of various sizes were dispersed throughout the cytoplasm including areas close to the plasma membrane (Fig. 3b,c). Large tubular structures containing rRab22b-EYFP appeared to extend from the center of the cell toward the periphery (Fig. 3a). Analysis of their distribution in consecutive focal planes indicates that some of these tubular formations originated in large asymmetric vesicles close to the nucleus (Fig. $3 \mathrm{e}-\mathrm{i})$. The chimera protein was also detected in small tubular structures $(1-6 \mu \mathrm{m})$ dispersed in different regions of the cytoplasm and in the cytosol (Fig. 3b). The localization pattern was independent of the expression level of rRab22b-EYFP, estimated by measuring fluorescence intensity (results not shown). Control experiments using unconjugated EYFP showed no localization in any sub- 

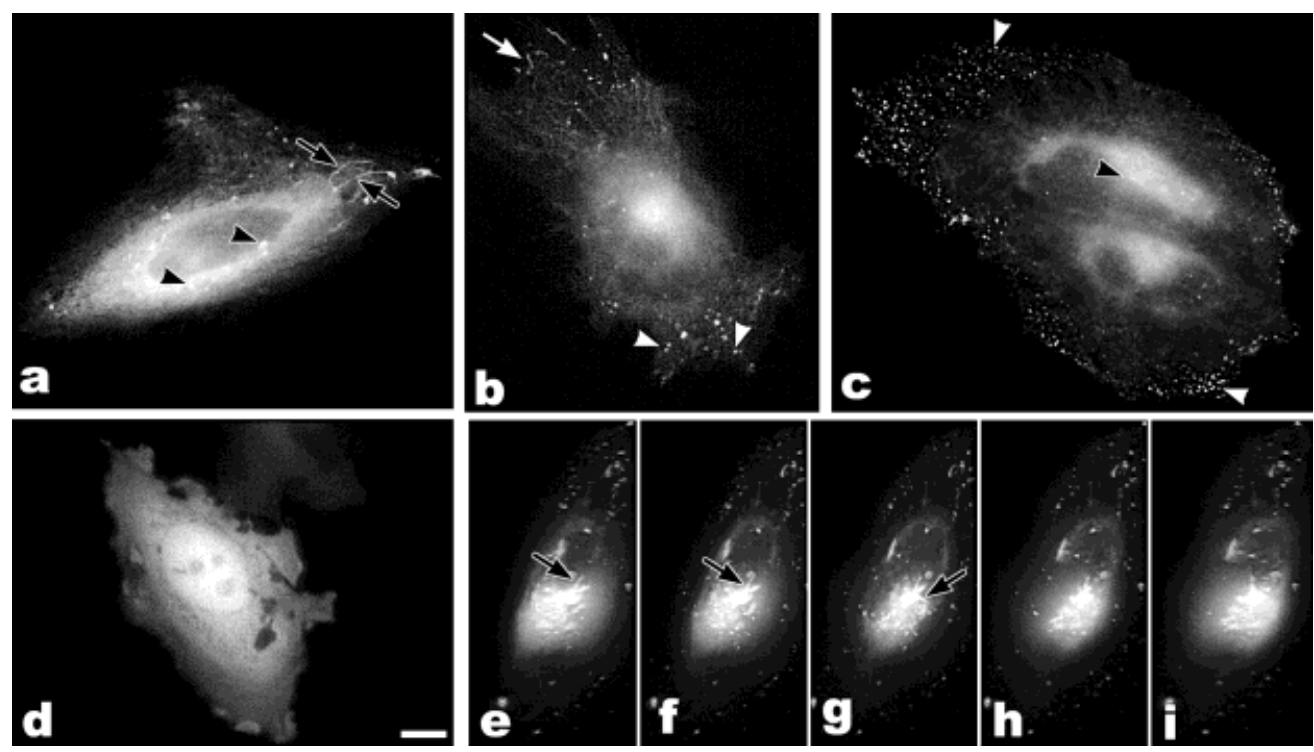

Fig. 3. Fluorescence microscopy of organelles in Hela cells expressing rRab22b-EYFP. Forty-eight hr after transfection cells were examined at $37^{\circ} \mathrm{C}$. A: Black arrowheads: large asymmetrical vesicles close to the nucleus, black arrows: two large tubular formations. B: White arrows small thin tubular formation, white arrow heads: small vesicles near the periphery. C: white arrowheads: same as in (B); black arrowhead same as in (A). D: Background staining with EYFP only. E-I: Serial $0.5 \mu \mathrm{m}$ optical sections. Images are stereo projections using the maximum pixel method. Black arrows: large tubular formations extending from asymmetrical vesicles closed to the nucleus. Scale bar $=10 \mu \mathrm{m}$. See animated movie sequence of e through 1 at Wiley InterScience (http:// www.wiley.interscience.com). cellular structures. There was an even distribution of fluorescence throughout the cell including the nucleus. This observation indicates that $\mathrm{rRab} 22 \mathrm{~b}-\mathrm{EYFP}$ chimera protein is targeted to specific structures.

\section{Movement and Plastic Changes of Organelles Containing rRab22b}

The dynamics of organelles containing $r R a b 22 b$ were studied to visualize the transport processes regulated by rRab22b. Intracellular traffic of membranes takes place via vesicles that bud from the donor compartment and then target selectively to the acceptor compartment (Nuoffer and Balch, 1994; Rothman and Wieland, 1996). Travel between compartments occurs along elements of the cytoskeleton (Nuoffer and Balch, 1994).

Movement and changes in the morphology of organelles containing rRab22b-EYFP were examined in digital time lapse images of chimera-expressing HELA cells. Analysis of time lapse images captured at 15-sec intervals showed that the large asymmetrical fluorescent structures close to the nucleus did not appear to move consistently in a single direction (Fig. 4). We observed large tubular structures extending, up to $25 \mu \mathrm{m}$, from the cell center to the periphery (Fig. 4a,b). Some seemed to come from asymmetrical vesicles localized close to the nucleus (Fig. 4b). These tubular structures appeared to be flexible, to undulate while extending and to bend while changing direction of movement. Sometimes, these structures appeared to interact with vesicular organelles present in the cell periphery (Fig. 4a).
Our results indicate that the asymmetrical vesicles and the larger tubular organelles localized close to the nucleus are the donor compartments. Indeed, we observed budding of small tubular vesicles from these structures (Fig. 5a,b). The small tubular vesicles containing rRab22b had kinetic and plastic properties similar to those associated with post Golgi carriers (Hirschberg et al., 1998). These small organelles moved intermittently along either straight or curvilinear tracks toward the cell periphery (approximately $0.2-0.6 \mu \mathrm{m} / \mathrm{sec}$ ), and they frequently changed direction. Some contained swollen or spherical areas along their length (Fig. 6a,b). The spherical areas were not stationary, and their content of rRab22b was higher than in other parts of the formation. Small tubular organelles underwent drastic shape changes, e.g., rounding into spherical shapes that would then become elongated in the direction of movement (Fig. 6a). They also displayed elastic properties, such as extension and retraction during movement. Occasionally, when they broke up, one fragment remained stationary whereas the other moved off (Fig. 6b). These tubular formations fused with small vesicles. In Figure 6b, a tubular formation has a higher fluorescence in one end whereas a vesicle interacts briefly with the other end. This interaction did not result in vesicle fusion and the vesicle moved away from the formation. Immediately the fluorescence intensity at this end increased and a second interaction between the vesicle and the tubular formation occurred. This time the vesicle did fuse. The new structure then broke into spherical vesicles. 


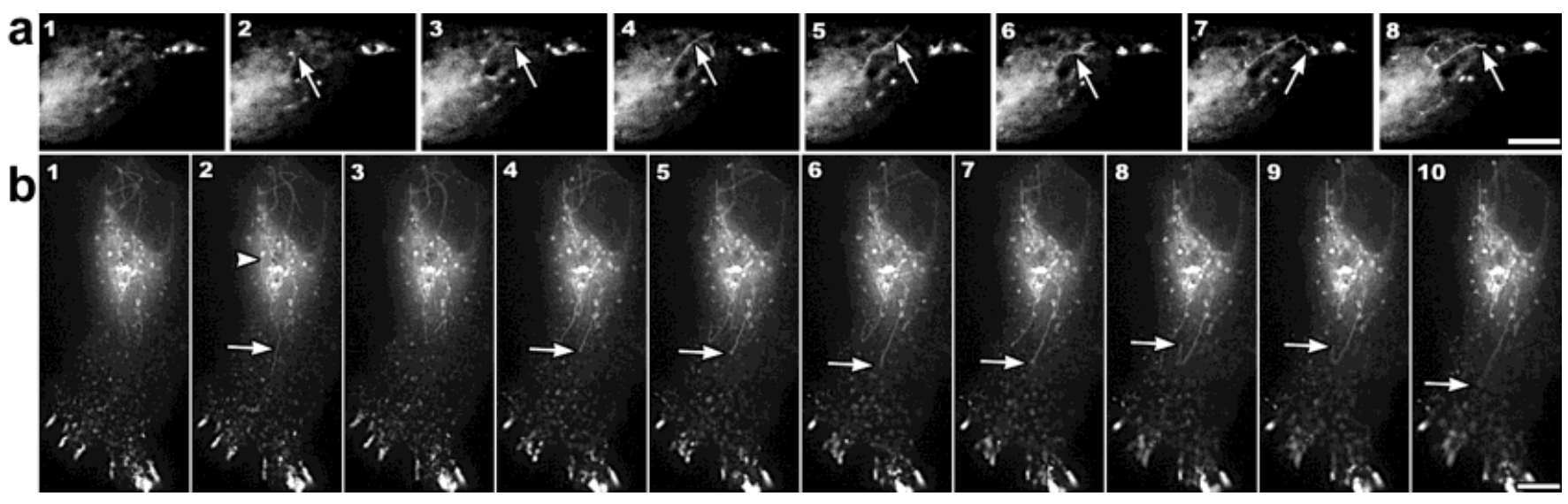

Fig. 4. Formation and movement of large tubular organelles containing rRab22b-EFYP. Hela cells were treated as in Figure 3. Selection of images captured at $15 \mathrm{sec}$ intervals for $6 \mathrm{~min}$ period. A: A brightly-labeled tubular formation (white arrow) extends from the center of the cell and makes contact with a vesicle located in the cell periphery. B: Large tubular formation (white arrow) emerging from intensively labeled asymmetrical vesicles (white arrowhead). Scale bar $=10 \mu \mathrm{m}$. See movie sequence at Wiley InterScience (http://www.wiley.interscience.com).

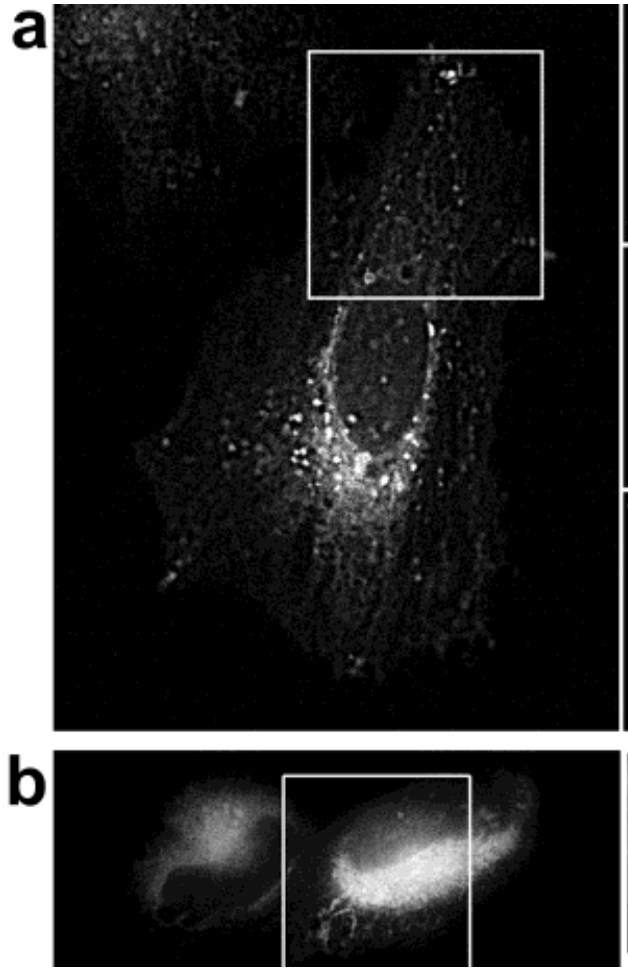

Fig. 5. Formation of small tubular vesicles involved in transport. Hela cells treated as in Figures 3 and 4. Time lapse images obtained as in Figure 4. A: Small tubular vesicle budding from a rRab22b labeled vesicle close to the nucleus also contains rRab22b. Large panel indicates restricted area shown in small frames covering $10.5 \mathrm{~min}$. Arrow shows

In some cells, intensive traffic was seen of small tubular vesicles going between the large asymmetrical structures localized close to the nucleus, and a cluster of tubular organelles localized in the cell periphery close to budding tubular vesicle and its movement toward the cell periphery. B: Small tubular vesicle (white arrowhead) forms from large tubular formation (white arrow). Large panel indicates restricted area shown in small frames covering $4.5 \mathrm{~min}$. Scale bar $=10 \mu \mathrm{m}$. See movie sequence at Wiley InterScience (http://www.wiley.interscience.com).

the plasma membrane (Fig. 7a). The small tubulo vesicular structures moved along defined pathways in both anterograde and retrograde directions. The clusters moved parallel to the plasma membrane, and tubulo vesicular or- 

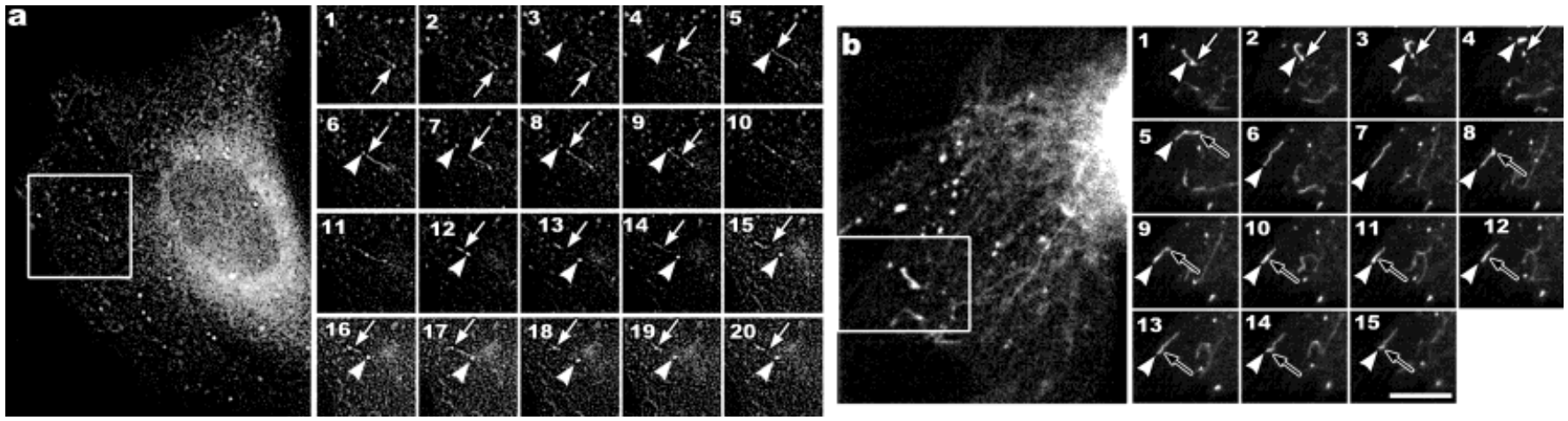

Fig. 6. Processing of organelles containing rRab22b. Hela cells treated as in Figure 3. Time lapse images obtained as in Figure 4. A: Small tubular formation (white arrow) moves toward cell periphery and fuses (Panel 9) with a small vesicle (white arrowhead) after rRab22b intensity increases (Panel 8) in the region of interaction. The new formation with higher centrally located rRab22b intensity (Panels 10 and 11) then divides (Panel 12) into smaller organelles (white arrowhead and white arrow, Panels 12 to 20). Large panel indicates restricted area shown in small frames covering 9.5 min. B: Small tubular formation divides into spherical (white arrow) and tubular (white arrowhead) vesicles. The latter then rounds up and moves away becoming elongated in the direction of movement. The vesicle shows varicosities of higher $\mathrm{rRab} 22 \mathrm{~b}$ intensity. Large panel indicates restricted area shown in small frames covering $3.75 \mathrm{~min}$. Scale bar $=10 \mu \mathrm{m}$. See movie sequence at Wiley InterScience (http://www.wiley.interscience.com). ganelles became detached and moved close to the plasma membrane. These observations indicate that: 1) the acceptor compartment is the cluster of organelles localized close to the plasma membrane; and 2) organelles containing rRab22b move along elements of the cytoskeleton.

The treatment of the cells with nocodazole $(10 \mu \mathrm{M}$ for $3 \mathrm{~min}$ ), an inhibitor of microtubule polymerization (Rogalski and Singer, 1984), disrupted the movement of organelles in the cell periphery (Fig. 7b). The cluster of tubular formations now was stationary and dispersed, with no movement of vesicles from the cell periphery toward the center. However, some small vesicles moved from the perinuclear area and fused with tubular organelles located in the cell periphery, further supporting the conclusion that these tubular organelles are the acceptor compartment. Additionally, from the data it appears that intact microtubules are required for directed transport of tubular structures containing rRab22b. Because treatment of the cell with $10 \mu \mathrm{M}$ cytochalasin B did not affect the kinetic behavior of organelles containing rRab22b actin microfilaments are not involved (Cooper, 1987). (Quick-time movies $7 \mathrm{c}, \mathrm{d})$.

\section{Identification of Subcellular Compartments Containing rRab22b}

To identify the subcellular organelles that contain rRab22b cells were cotransfected with rRab22b-EYFP together with other markers tagged with ECFP (a cyano variant of green fluorescent protein). These included Rab8 (trans Golgi) (Huber et al., 1993), Rab5b (early endosomes) (Gorvel et al., 1991), Rab7 (late endosomes) (Meresse et al., 1995) and pECFP-Golgi (a chimera constructed with ECFP and an 81 amino acid fragment of the $\mathrm{N}$ terminal region of human 1,4 beta galactosyl transferase localizing mainly in the trans-Golgi) (Llopis et al., 1998) (Fig. 8). Our results and those from other laboratories demonstrated that the tagging of these intracellular markers did not affect their localization (Llopis et al., 1998; Roberts et al., 1999; Bucci et al., 2000; Sonnichsen et al., 2000). Large asymmetric vesicles containing both rRab22b and Rab8 localized closed to the nucleus (Fig. $8 \mathrm{a}-\mathrm{c})$. Similarly, some large tubular formations extending from the center of the cell to the periphery also contained both proteins, indicating that these structures containing rRab22b are part of the trans Golgi network (TGN). The localization of rRab22b in trans-Golgi is supported by the colocalization of rRab22b-EYFP and pECFP-Golgi (Fig. $8 d-f)$. rRab22b partially colocalized in small vesicles with Rab5 (Fig. 8g-i). Similarly, some vesicles contained both Rab22b and Rab7 (Fig. 8g-1), suggesting that rRab22b is also present in organelles of the endocytic pathway.

A cluster of tubular organelles located close to areas of the plasma membrane where membrane extensions are formed was identified as early endosomes because these organelles also contained Texas Red-transferrin (after incubation of cells for 5 min with Texas-Red labeled transferrin) (Fig. $8 \mathrm{~m}-\mathrm{o}$ ).

\section{Expression of a rRab22b Mutant (S19N) Tagged With EYFP}

Our previous results indicated that $\mathrm{rRab} 22 \mathrm{~b}$ regulates the transport of vesicles between the trans Golgi and the endocytic compartment. The role of Rab proteins in regulating intracellular transport relies on two properties: 1) the ability to alternate between two conformational states (GDP-bound, active and GTP-bound, inactive), and 2) the capacity to bind to specific membrane compartments, donor compartment, inactive state; acceptor compartment, active state. Dominant negative mutants with altered guanine nucleotide-binding properties inhibit vesicle transport both in vivo and in vitro (Olkkonen and Stenmark, 1997). Substitution of S by $\mathrm{N}$ in the last residue 


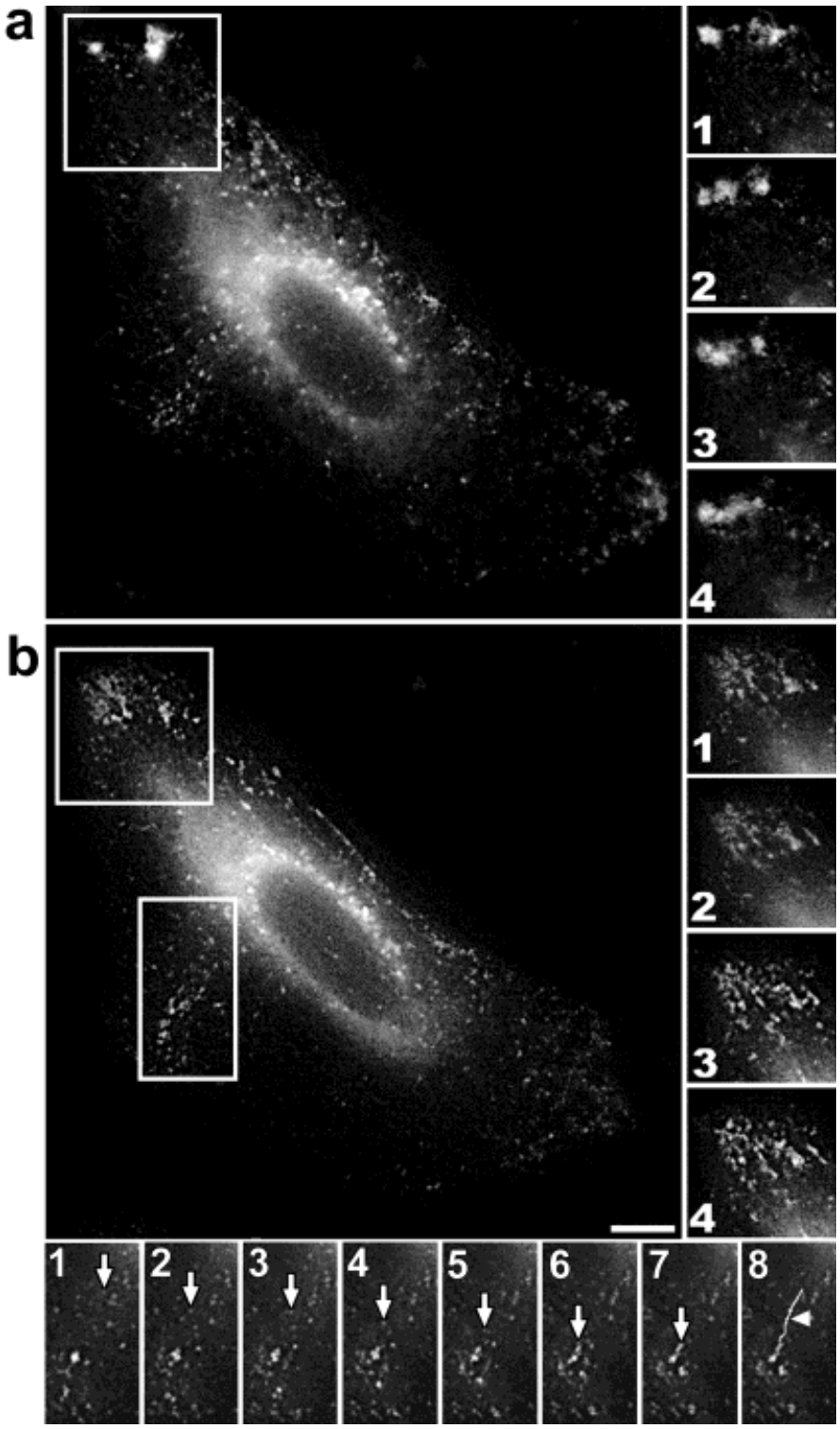

Fig. 7. Movement of $r$ Rab22b vesicles before and after disruption of microtubules. Hela cells were examined $48 \mathrm{hr}$ after transfection. Time lapse images obtained as in Figure 4. A: Before disruption of microtubules a highly mobile cluster of tubular organelles, localized in the cell periphery moves rapidly along the plasma membrane (small frames, left). Large panel indicates restricted area shown in small frames covering $7.5 \mathrm{~min}$. B: After treatment of cells with nocodazole $(10 \mu \mathrm{M}$, $3 \mathrm{~min}$ ) movement is disrupted, and the cluster of organelles disperses (frames panels, left). A small vesicular organelle (white arrow, bottom small frames 1 to 7) travels from the center of the cell to the cell periphery and fuse with tubular organelle (head arrow, vesicle trajectory, frame 8). Large panel indicates restricted areas shown in small frames covering $7.5 \mathrm{~min}$. Scale bar $=10 \mu \mathrm{m}$. See movie sequence at Wiley InterScience (http://www.wiley.interscience.com).

of the first GTP binding motif of Rab1 results in a protein that probably remains in the GDP-bound state, thereby inhibiting transport between ER and Golgi (Nuoffer and Balch, 1994). When we substituted the 19 S residue by $\mathrm{N}$ in the cDNA rRab22b sequence and expressed this mutant (tagged with EYFP) in Hela cells image analysis showed localization mainly in asymmetrical vesicular and tubular compartments close to the nucleus (Fig. 9). Moreover, no vesicle budding from these organelles was seen (Fig. 9). The fact that $\mathrm{rRab} 22 \mathrm{~b}$ mutant co-localized with pECFPGolgi showed that both of these perinuclear compartments are part of the trans-Golgi (Fig. 10). These results are consistent with the view that $\mathrm{rRab} 22 \mathrm{~b}$ regulates the transport of vesicles from the trans-Golgi to an endocytic compartment.

\section{Oligodendrocyte Cultures}

After $24 \mathrm{hr}$ of transfection of the chimera protein of rRab22b with EYFP in rat oligodendrocyte cultures, up to $2 \%$ of oligodendrocytes expressed rRab22b-EYFP, an expression that persisted for the 4 days of the experimental period. Transfection did not produce an increase in the number of dead cells or a change in oligodendrocyte morphology.

Similar to the observations in Hela cells, rRab22b was localized in large asymmetric vesicles close to the nucleus and was also present in organelles in oligodendrocyte processes (Fig. 11). These results indicate that in oligodendrocytes and their processes as well as in Hela cells $\mathrm{rRab} 22 \mathrm{~b}$ regulates the transport of vesicles between the trans Golgi and endocytic compartments.

\section{DISCUSSION}

We are studying the function of $\mathrm{rRab} 22 \mathrm{~b}$ in relation to its role in myelin formation. rRab22b is a novel rat Rab protein we detected in a rat cDNA library specific for oligodendrocytes, the cells that produce myelin.

To study rRab22b function we have constructed a fusion protein with EYFP. Because the C terminal of Rab proteins is subject to post-translational isoprenylation, a modification essential for both membrane association and interaction with effector proteins (Chavrier et al., 1991; Olkkonen and Stenmark, 1997), the N terminal was used for tagging. Although the $\mathrm{N}$ terminal sequence is important for Rab function (Tisdale and Balch, 1996), tagging this terminal does not alter function (Bucci et al., 2000; Roberts et al., 1999; Sonnichsen et al., 2000).

By expressing this fusion protein in living cells we followed both the intracellular localization of rRab22b in vesicles and the movement of these vesicles.

Two properties of rRab22b, GTP-binding and the presence of terminal isoprenylation sites, indicate its probable targeting to membrane compartments. Participation in regulation of membrane traffic from trans Golgi to early endocytic compartments is shown by the following observations obtained with Hela cells: 1) rRab22b was mainly localized in asymmetrical vesicles and large tubular formations in the trans Golgi and TGN; and 2) rRab22b was present in early endocytic compartments in the cell periphery. Moreover, the mutant of rRab22b (N19S) behaved very differently. It localized only in the trans Golgi compartment. 
This difference in behavior of the mutant N19S also clearly indicates that the distribution pattern of $\mathrm{rRab} 22 \mathrm{~b}$ in both donor and acceptor compartments does not result from over-expression of the chimera proteins, because the substitution of serine by asparagine in position 19 restricts localization to the donor compartment. Other consider-
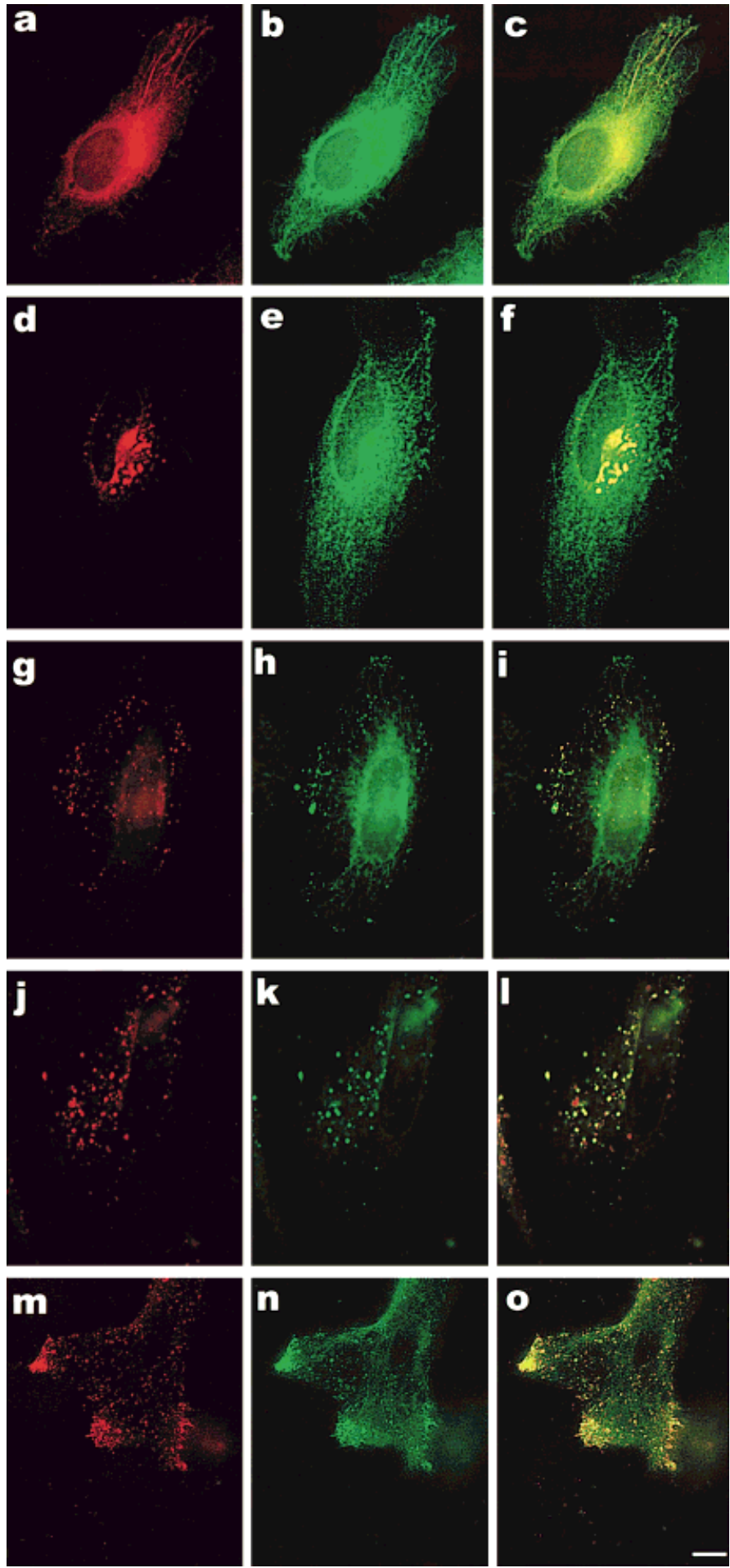
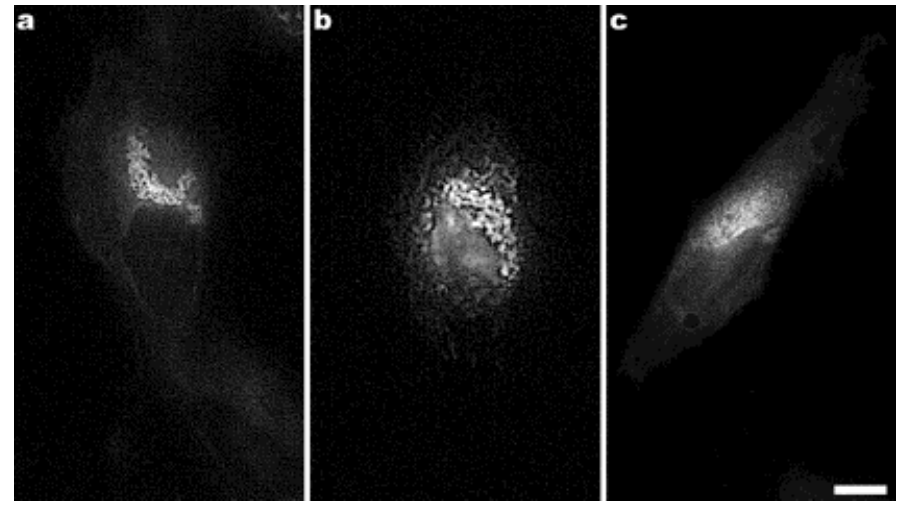

Fig. 9. Mutant rRab22b (S19N) localization is restricted to large tubular formations and asymmetrical vesicles close to the nucleus. A-C: Images of three different cells examined $48 \mathrm{hr}$ after transfection. Quick movies show organelles with rRab22b mutant vibrate only in place. Scale bar $=10 \mu \mathrm{m}$. For $\mathrm{a}$ and $\mathrm{b}$ see movie sequence at Wiley InterScience (http://www.wiley.interscience.com)
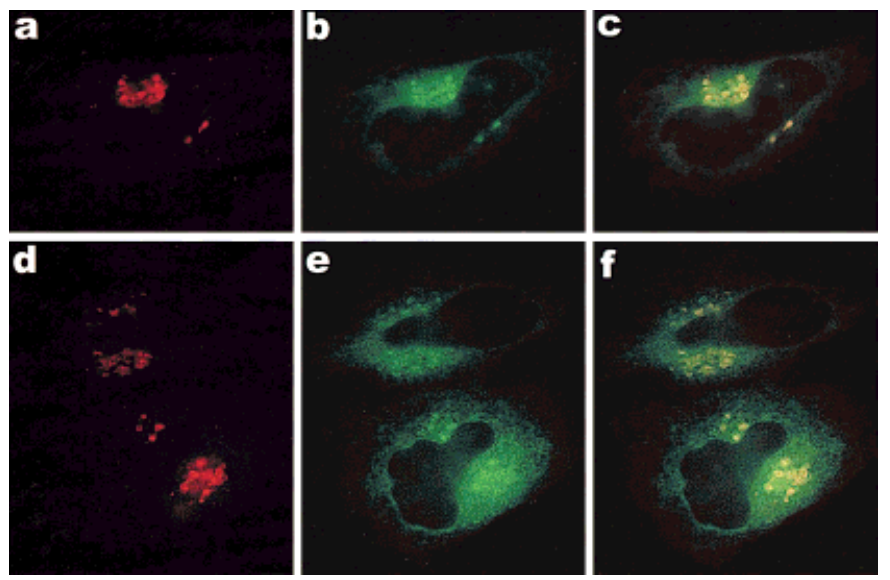

Fig. 10. Mutant rRab22b (S19N) colocalizes with trans Golgi marker. Cells were examined $48 \mathrm{hr}$ after cotransfection. A,D: rRab22b-EYFP (S19N) mutant; B,E: Golgi pECFP (trans-Golgi); C,F: overlapping (yellow organelles) of rRab22b-EYFP (S19N) mutant and Golgi pECFP. Scale bar $=10 \mu \mathrm{m}$.

Fig. 8. Presence of rRab22b in TGN, trans Golgi, early endosomes and late endosomes by colocalization with compartment markers. Cells were examined $48 \mathrm{hr}$ after cotransfection. A: rab8-ECFP (TGN); B: rRab22b-EYFP; C: overlapping of (A) and (B), yellow organelles contain both Rab8-ECFP and rRab22b-EYFP. D: Golgi pECFP (trans-Golgi); E: rRab22b-EYFP; F: overlapping of (D) and (E). Color as before. G: Rab5-ECFP (early endosomes); H: rRab22b-EYFP; I: overlapping of $(\mathrm{G})$ and $(\mathrm{H})$. Color as above. J: Rab7-ECFP (late endosomes); K: rRab22b-EYFP; L: overlap of (J) and (K). Color as above. M: Transferrin-Texas Red (early endosomes); N: rRab22bEYFP; O: overlapping of (M) and (N). Color as above. Scale bar $=10$ $\mu \mathrm{m}$. For $\mathrm{m}-\mathrm{o}$ see movie sequence at Wiley InterScience (http://www. wiley.interscience.com). 

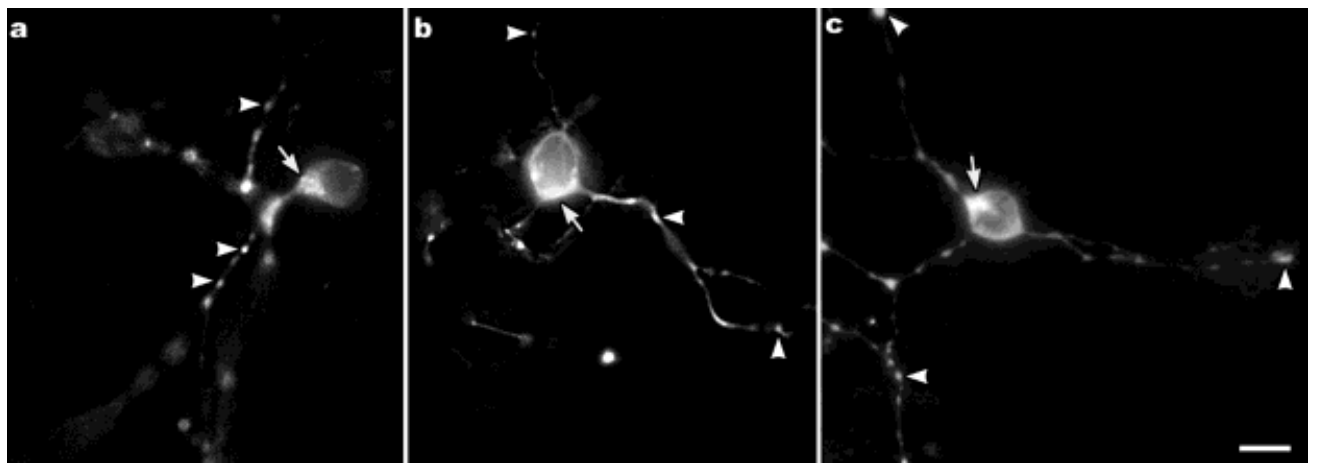

Fig. 11. rRab22b in oligodendrocyte perikaryon and its processes. A-C: Asymmetrical vesicles containing rRab22b localize close to the nucleus (white arrow) and organelles (white arrowhead) are present in oligodendrocyte processes. Images were taken $48 \mathrm{hr}$ after transfection. Scale bar $=$ $10 \mu \mathrm{m}$.

ations also argue against over-expression as a factor in these localizations. First, the distribution pattern of rRab22bEYFP was independent of the level of expression. Second, over-expression did not appear to affect localization of Rab5-ECFP and Rab7-ECFP. Third, recent studies showed that over-expression of Rab tagged with GFP did not affect the intracellular localization (Bucci et al., 2000; Roberts et al., 1999; Sonnichsen et al., 2000).

Our observations indicate that small tubovesicular organelles containing rRab22b that bud from the trans Golgi and fuse with endocytic compartments in the cell periphery are the mechanism of transport of membrane constituents from the trans Golgi to endocytic compartments. These organelles have morphological and kinetic properties similar to those presented by post Golgi carriers (Nakata et al., 1998; Toomre et al., 1999). These properties are: 1) the presence of spherical areas along their length; 2) the drastic changes in shape that they undergo; 3) their ability to break up or fuse with small vesicles; 4) their movement along tracts towards the cell periphery (at approximately $0.2-0.6 \mu \mathrm{m} / \mathrm{sec}$ ) with frequent changes in direction; and 5) the involvement of microtubules in their transport.

Because rRab22b was also present in late endosomes, one cannot exclude involvement of this protein in membrane traffic from early to late endosomes. Other Rab proteins are known to participate in more than one step in membrane trafficking (Novick and Zerial, 1997).

The concentration of rRab22b was higher in some organelle regions where fusion with small tubular formations occurred. Although the functional relation is not clear, a similar observation with a different $\mathrm{Rab}$ protein, Rab5a, was reported in the area of contact of fusing endosomes (Roberts et al., 1999).

In addition to regulation of directional movement, rRab22b appears to be involved in the formation of small vesicles, because expression of the rRab22b mutant (N19S) was not seen in vesicles budding from the trans Golgi. According to previous evidence, Rab proteins participate both in the targeting of vesicles and in the budding of vesicles (Jedd et al., 1997; McLauchlan et al., 1998; Jones et al., 1999). These results show that $\mathrm{rRab} 22 \mathrm{~b}$ is not simply that of a passenger, but plays a functional role in transport.
Our results indicate that one mechanism of transport of membrane constituents from the trans Golgi to endosomes involves distinct vesicles. Direct transfer of membrane components from the TGN to other organelles also needs to be considered because large tubular formations of the TGN containing rRab22b extend toward the cell periphery and interact with spherical vesicles there. Both cis and trans cisternae of the Golgi are composed of extensive tubular networks (Sasaki et al., 1984; Jahn, 2000) that can be generated rapidly by Golgi membranes in vivo and in vitro under diverse conditions (Cluett et al., 1993; Banta et al., 1995). This mediation by tubules of membrane traffic between organelles is more clearly observed in cells treated with brefeldin A (Sciaky et al., 1997).

In oligodendrocyte cultures we find that: 1) a high level of rRab22b mRNA is present in differentiated oligodendrocytes whereas such expression in their progenitors is very low; 2) $\mathrm{rRab} 22 \mathrm{~b}$ is present in trans Golgi/TGN vesicles; and 3) rRab22b is present in endosomic organelles in oligodendrocyte processes.

These observations, especially the level of $r$ Rab22b mRNA suggest that trafficking of membrane components from the trans-Golgi to endocytic compartments regulated by $\mathrm{rRab} 22 \mathrm{~b}$ is an important step in myelin formation and maintenance. Because $\mathrm{rRab} 22 \mathrm{~b}$ mRNA is present in other cell types, the step in vesicular traffic that rRab22b regulates is probably not unique to oligodendrocytes.

That certain proteins, such as transferrin receptor and asialoglycoprotein receptor $\mathrm{H} 1$, are carried from the trans Golgi to an endocytic compartment before reaching the cell surface (Futter et al., 1995; Leitinger et al., 1995) lends support to the inference that this pathway is involved in myelin formation.

The cytoplasmic tail of these proteins contains the motif YXX $\phi$, where $X$ is any amino acid and $\phi$ is an amino acid containing a bulky hydrophobic residue. Evidence shows that the YXX $\phi$ motif, originally known for mediating rapid internalization from the cell surface (Bonifacino and Dell'Angelica, 1999) is also now recognized for mediating trans Golgi sorting mechanisms that target proteins to endocytic compartments (Bonifacino and Dell'Angelica, 1999). The sequence of large MAG shows a segment in its carboxyl terminal region that conforms to the consensus motif YXX $\phi$, YAEI. This se- 
quence suggests that large MAG is transported from trans Golgi to endocytic compartments, and our results in Hela cells further suggest that this pathway is regulated by rRab22b. Indeed, endocytic compartments containing MAG are observed in oligodendrocyte processes including areas close to the axon where active formation of myelin occurs (Trapp et al., 1989; Bo et al., 1995).

These conclusions are in accord with the presence of rRab22b in endocytic compartments of oligodendrocyte processes, endocytic compartments that in Hela cells localize close to areas where plasma membrane extensions occur.

rRab22b may also be involved in the biogenesis of endosomes because early endosomes receive newly synthesized proteins that have been sorted in the trans Golgi network before being transported to late endosomes (Peters and von Figure, 1994; Jackson et al., 1995).

The importance of the rRab22b dependent membrane trafficking to endosomes is particularly relevant because: 1) this compartment is involved in the remodeling of myelin that occurs toward the end of the period of active myelination (Raine, 1984);2) continuous cycles of lamella extension and retraction are observed in oligodendrocyte cultures (Kachar et al., 1986), cycles that underlie substrate exploration to find and wrap the axon in the myelin sheath (Kachar et al., 1986); and 3) proteins that are not essential but are required for assembly need to be eliminated from myelin (Gould et al., 2000).

Endocytic processes of importance in oligodendrocytes involve a number of Rab proteins including Rab5a, Rab5b, and Rab5c (Burcelin et al., 1997; Bouverat et al., 2000). It should be noted that the levels of their expression increase with oligodendrocyte differentiation (Bouverat et al., 2000).

In summary, our observations clearly indicate that $\mathrm{rRab} 22 \mathrm{~b}$ is involved in the regulation of membrane trafficking from trans Golgi compartments to endocytic compartments and further suggest that $r$ Rab22b participates in the formation of vesicles budding from the trans Golgi.

\section{ACKNOWLEDGMENTS}

We thank Dr. Maurice Rapport for editing and commenting on the manuscript. This work was supported by NMS RG 1941 and NSF ABN-9983255 (JNL), NIH DK47245 and AECOM Cancer Center Grant 5P30CA13330 (MJC), and MRC MT-12734 (GA).

\section{REFERENCES}

Baba H, Fuss B, Urano J, Poullet P, Watson JB, Tamanoi F, Macklin WB. 1995. GapIII, a new brain-enriched member of the GTPase-activating protein family. J Neurosci Res 41:846-858.

Banta M, Polizotto RS, Wood SA, de Figueiredo P, Brown WJ. 1995. Characterization of a cytosolic activity that induces the formation of Golgi membrane tubules in a cell-free reconstitution system. Biochemistry 34:13359-13366.

Barbarese E, Koppel DE, Deutscher MP, Smith CL, Ainger K, Morgan F, Carson JH. 1995. Protein translation components are colocalized in granules in oligodendrocytes. J Cell Sci 108:2781-2790.

Benjamins JA, Smith ME. 1984. Metabolism of myelin. In: Morell P, editor. Myelin. 225-258. 1984. New York, London: Plenum Press. p. 225-258.

Berti Mattera LN, Larocca JN, Pellegrino de Iraldi A, Pasquini JM, Soto E. 1984. Isolation of oligodendroglial cells from young and adult whole rat brains using an in situ generated percoll density gradient. Neurochem Int 6:41-51.

Bo L, Quarles RH, Fujita N, Bartoszewicz Z, Sato S, Trapp BD. 1995. Endocytic depletion of L-MAG from CNS myelin in quaking mice. J Cell Biol 131:1811-1820.

Bonifacino JS, Dell'Angelica EC. 1999. Molecular bases for the recognition of tyrosine-based sorting signals. J Cell Biol 145:923-926.

Bourne HR, Sanders DA, McCormick F. 1990. The GTPase superfamily: a conserved switch for diverse cell functions. Nature 348:125-132.

Bouverat BP, Krueger WH, Coetzee T, Bansal R, Pfeiffer SE. 2000. Expression of rab GTP-binding proteins during oligodendrocyte differentiation in culture. J Neurosci Res 59:446-453.

Bucci C, Thomsen P, Nicoziani P, McCarthy J, van Deurs B. 2000. Rab7: a key to lysosome biogenesis. Mol Biol Cell 11:467-480.

Burcelin R, Rodriguez-Gabin AG, Charron MJ, Almazan G, Larocca JN. 1997. Molecular analysis of the monomeric GTP-binding proteins of oligodendrocytes. Brain Res Mol Brain Res 50:9-15.

Chavrier P, Gorvel JP, Stelzer E, Simons K, Gruenberg J, Zerial M. 1991. Hypervariable C-terminal domain of rab proteins acts as a targeting signal. Nature 353:769-772.

Chen D, Guo J, Miki T, Tachibana M, Gahl WA. 1996. Molecular cloning of two novel rab genes from human melanocytes. Gene 174:129-134.

Cluett EB, Wood SA, Banta M, Brown WJ. 1993. Tubulation of Golgi membranes in vivo and in vitro in the absence of brefeldin A. J Cell Biol 120:15-24.

Cole NB, Lippincott-Schwartz J. 1995. Organization of organelles and membrane traffic by microtubules. Curr Opin Cell Biol 7:55-64.

Colman DR, Kreibich G, Frey AB, Sabatini DD. 1982. Synthesis and incorporation of myelin polypeptides into CNS myelin. J Cell Biol 95:598-608.

Cooper JA. 1987. Effects of cytochalasin and phalloidin on actin. J Cell Biol 105:1473-1478

Filbin MT, Walsh FS, Trapp BD, Pizzey JA, Tennekoon GI. 1990. Role of myelin P0 protein as a homophilic adhesion molecule. Nature 344:871872.

Futter CE, Connolly CN, Cutler DF, Hopkins CR. 1995. Newly synthesized transferrin receptors can be detected in the endosome before they appear on the cell surface. J Biol Chem 270:10999-11003.

Gorvel JP, Chavrier P, Zerial M, Gruenberg J. 1991. Rab5 controls early endosome fusion in vitro. Cell 64:915-925.

Gould RM, Freund CM, Palmer F, Feinstein DL. 2000. Messenger RNAs located in myelin sheath assembly sites. J Neurochem 75:1834-1844.

Gow A, Lazzarini RA. 1996. A cellular mechanism governing the severity of Pelizaeus-Merzbacher disease. Nat Genet 13:422-428.

Hirschberg K, Miller CM, Ellenberg J, Presley JF, Siggia ED, Phair RD, Lippincott-Schwartz J. 1998. Kinetic analysis of secretory protein traffic and characterization of golgi to plasma membrane transport intermediates in living cells. J Cell Biol 143:1485-1503.

Ho SN, Hunt HD, Horton RM, Pullen JK, Pease LR. 1989. Site-directed mutagenesis by overlap extension using the polymerase chain reaction [see comments]. Gene 77:51-59.

Huber LA, Pimplikar S, Parton RG, Virta H, Zerial M, Simons K. 1993. Rab8, a small GTPase involved in vesicular traffic between the TGN and the basolateral plasma membrane. J Cell Biol 123:35-45.

Jackson MR, Fruh K, Karlsson L, Teyton L, Yang Y, Peterson PA. 1995. Assembly and intracellular transport of MHC class I and class II molecules. Cold Spring Harb Symp Quant Biol 60:249-261.

Jahn R. 2000. Sec1/Munc18 proteins: mediators of membrane fusion moving to center stage. Neuron 27:201-204. 
Jedd G, Mulholland J, Segev N. 1997. Two new Ypt GTPases are required for exit from the yeast trans-Golgi compartment. J Cell Biol 137:563-580.

Jones S, Jedd G, Kahn RA, Franzusoff A, Bartolini F, Segev N. 1999. Genetic interactions in yeast between Ypt GTPases and Arf guanine nucleotide exchangers. Genetics 152:1543-1556.

Kachar B, Behar T, Dubois-Dalcq M. 1986. Cell shape and motility of oligodendrocytes cultured without neurons. Cell Tissue Res 244:27-38.

Leitinger B, Hille-Rehfeld A, Spiess M. 1995. Biosynthetic transport of the asialoglycoprotein receptor $\mathrm{H} 1$ to the cell surface occurs via endosomes. Proc Natl Acad Sci USA 92:10109-10113.

Llopis J, McCaffery JM, Miyawaki A, Farquhar MG, Tsien RY. 1998. Measurement of cytosolic, mitochondrial, and Golgi $\mathrm{pH}$ in single living cells with green fluorescent proteins. Proc Natl Acad Sci USA 95:6803-6808

Maniatis F, Fristsch EP, Sambrook J. 1989. Molecular cloning: a laboratory manual. 1989. Cold Spring Harbor, NY: Cold Spring Harbor Laboratory Press.

McCarthy KD, de Vellis J. 1980. Preparation of separate astroglial and oligodendroglial cell cultures from rat cerebral tissue. J Cell Biol 85:890902 .

McLauchlan H, Newell J, Morrice N, Osborne A, West M, Smythe E. 1998. A novel role for Rab5-GDI in ligand sequestration into clathrincoated pits. Curr Biol 8:34-45.

Meresse S, Gorvel JP, Chavrier P. 1995. The rab7 GTPase resides on a vesicular compartment connected to lysosomes. J Cell Sci 108:33493358.

Morel P, Quarles R, Norton WT. 1994. Myelin formation, structure, and biochemistry. In: Siegel GJ, editor. Basic neurochemistry: molecular, cellular, and medical aspects. New York: Raven Press. p. 147-195.

Nakata T, Terada S, Hirokawa N. 1998. Visualization of the dynamics of synaptic vesicle and plasma membrane proteins in living axons. J Cell Biol 140:659-674.

Novick P, Zerial M. 1997. The diversity of Rab proteins in vesicle transport. Curr Opin Cell Biol 9:496-504.

Nuoffer C, Balch WE. 1994. GTPases: multifunctional molecular switches regulating vesicular traffic. Annu Rev Biochem 63:949-990.

Olkkonen VM, Stenmark H. 1997. Role of Rab GTPases in membrane traffic. Int Rev Cytol 176:1-85.

Ossig R, Laufer W, Schmitt HD, Gallwitz D. 1995. Functionality and specific membrane localization of transport GTPases carrying C-terminal membrane anchors of synaptobrevin-like proteins. EMBO J 14:36453653.

Pedraza L, Fidler L, Staugaitis SM, Colman DR. 1997. The active transport of myelin basic protein into the nucleus suggests a regulatory role in myelination. Neuron 18:579-589.

Peters C, von Figura K. 1994. Biogenesis of lysosomal membranes. FEBS Lett 346:108-114.

Raine CS. 1984. Morphology of myelin and myelination. In: Morell P, editor. Myelin. New York, London: Plenum Press. p. 1-41.

Roberts RL, Barbieri MA, Pryse KM, Chua M, Morisaki JH, Stahl PD. 1999. Endosome fusion in living cells overexpressing GFP-rab5. J Cell Sci 112:3667-3675

Rogalski AA, Singer SJ. 1984. Associations of elements of the Golgi apparatus with microtubules. J Cell Biol 99:1092-1100.

Rothman JE, Wieland FT. 1996. Protein sorting by transport vesicles. Science 272:227-234.

Sasaki T, Motegi N, Higashi S. 1984. Morphological analysis of the Golgi apparatus in rat amelogenesis as revealed by the $\mathrm{Ur}-\mathrm{Pb}-\mathrm{Cu}$ block staining method and freeze-fracture replication. J Electron Microsc (Tokyo) 33: 19-33.

Sato C, Schriftman M, Larocca JN. 1986. Transport of sulfatides towards myelin. Effect of colchicine, monensin and calcium on their intracellular translocation. Neurochem Int 9:247-252.

Sciaky N, Presley J, Smith C, Zaal KJ, Cole N, Moreira JE, Terasaki M, Siggia E, Lippincott-Schwartz J. 1997. Golgi tubule traffic and the effects of brefeldin A visualized in living cells. J Cell Biol 139:1137-1155.

Sonnichsen B, De Renzis S, Nielsen E, Rietdorf J, Zerial M. 2000. Distinct membrane domains on endosomes in the recycling pathway visualized by multicolor imaging of Rab4, Rab5, and Rab11. J Cell Biol 149:901-914.

Tisdale EJ, Balch WE. 1996. Rab2 is essential for the maturation of pre-Golgi intermediates. J Biol Chem 271:29372-29379.

Toomre D, Keller P, White J, Olivo JC, Simons K. 1999. Dual-color visualization of trans-Golgi network to plasma membrane traffic along microtubules in living cells. J Cell Sci 112:21-33.

Townsend LE, Benjamins JA. 1983. Effects of monensin on posttranslational processing of myelin proteins. J Neurochem 40:1333-1339.

Townsend LE, Benjamins JA, Skoff RP. 1984. Effects of monensin and colchicine on myelin galactolipids. J Neurochem 43:139-145.

Trapp BD, Andrews SB, Cootauco C, Quarles R. 1989. The myelinassociated glycoprotein is enriched in multivesicular bodies and periaxonal membranes of actively myelinating oligodendrocytes. J Cell Biol 109: $2417-2426$

Wallace RB, Schold M, Johnson MJ, Dembek P, Itakura K. 1981. Oligonucleotide directed mutagenesis of the human beta-globin gene: a general method for producing specific point mutations in cloned DNA. Nucleic Acids Res 9:3647-3656. 